\title{
ARTIG0S
}

\section{SENHORIO OU SOBERANIA DO INFANTE NA ILHA DA MADEIRA?}

Vamos estudar neste trabalho o problema da natureza das instituições políticas coloniais. Tomando-se como exemplo a Ilha da Madeira, temos três pontos a serem considerados: a) o problema; b) a problemática e c) linhas de pesquisa.

\section{I. - O problema.}

Com o início da expansão ultramarina, a partir efetivamente da conquista de Ceuta em 1415, novas terras e novos povos de alguma forma vão sendo incorporados ao complexo político-administrativo que era Portugal.

De que forma se processou êsse alargamento da esfera de autoridade do govêrno português, ou, em outros têrmos, qual a fórmula político-administrativa mediante a qual essas novas terras se enquadram no "estado" monárquico pré-existente?

Problema de construção institucional. Êsses territórios novos já povoados ou a povoarem-se, constituiram um simples prolongamento da terra portuguêsa, além do Algarve, estendendo-se pura e simplesmente a eficácia das instituições vigentes como se processara durante a Reconquista, ou, pelo contrário, erigiram-se em entidades político-administrativas originais à espera de novo estatuto jurídico, definindo-se como apêndices territoriais para cuja direção se fabricaram novas instituições?

Se os novos domínios figuram como extensão da obra das cruzadas de recuperação de solo cristão e desdobramento espacial do patrimônio do rei português, à inércia do movimento de recuperação corresponde uma existência institucional, $\mathrm{crm}$ suas características sensivelmente medievais.

Se, porém, as novas terras constituem não reconquistas, mas descobertas, áreas de uma experiência também nova, então podemos pensar que as instituições tradicionais não se ajustam à realidade nova.

Num caso, haveria um crescimento geográfico do patrimônio régio - como ocorreu com a incorporação do Algarve. 
Noutro, haveria a colocação do binômio metrópole-colônia e o segundo têrmo reclamaria um tratamento institucional diversificado, impondo uma dinâmica criadora.

E' a questão do início da obra colonial que condiciona seu desenvolvimento posterior, quando a autonomia institucional é bem definida.

Cabe ainda considerar-se que, se as instituições permanecem as mesmas aplicadas a novas áreas geográficas recuperadas para o mundo cristão - prolongamento do cruzadismo ibérico - essas instituições tendem a guardar seus caracteres medievalizantes residuais, apesar das inovações trazidas pela Revolução de 1383 . Mas, se se considera que o mundo novo que se revela significa um desafio à inventiva institucional um campo de nova experiência política, temos descobertas e não reconquistadas, essa experiência significa criação ou adaptação criadora de algo de novo, de moderno portanto.

$\mathrm{E}$ ainda. Em terras conquistadas ao infiel, estende-se, com a vida política, a vida religiosa, a vida econômica que apenas $\mathrm{S}$ : amplificam geogràficamente. Mas em terras novas, havidas em condições que não são de conflito militar, empreende-se ocupação com novas técnicas de vida. Sobretudo no plano ecorômico, dadas as novas condições sociais que se oferecem.

Assim, o problema que se oferece à nossa indagação é êste: na ocupação colonial da época henriquina quais são em seu sentido as instituições que se implantam? As instituições paramedievais do século XV definidamente portuguêsas, ou instituições novas, modernas, pròpriamente coloniais? $\mathrm{E}$ com as instituições, através de sua análise, configuram-se nas novas terras reedições do regime senhorial metropolitano, ou ensaiamse emprêsas de caráter para-burguês, com traços de modernidade?

Como exemplo típico escolhemos a ocupação da Ilha da Madeira, cronològicamente situada no limiar da grande emprêsa de expansão.

\section{II. - A problemática.}

Em relação ao apossamento da Ilha da Madeira por parte de Portugal, sua incorporação e colonização, havemos de considerar as seguintes questões:

$10^{\circ}$ - Qual a entidade política que tem a iniciativa de sua descoberta, e, em conseqüência a posse do patrimônio da Ilha. Essa questão é mais importante que saber-se simplesmente que indivíduos a descobriram, em que data, e se intencional ou ca- 
sualmente. Interessam os indivíduos para se saber a serviço de quem; as datas, para se conhecer a conjuntura política, a forma, para se indagar o sentido da iniciativa. Identificando-se a entidade, régia ou senhorial, nobre ou burguesa, militar ou civil, religiosa ou mercantil, temos elementos para saber que fôrças inspiram a ocupação do território e, portanto, como se dá o processo de sua incorporação. No caso, quem ocupa a Madeira: a Corôa, uma casa senhorial representada pelo Infante, uma Ordem Militar - a Ordem de Cristo - ou particulares (os descobridores)?

$2 .^{\circ}$ - Qual a justificação jurídico-moral ou decorrente de novas condições sociais e econômicas que inspira a tomada da Ilha pelos portuguêses? E' o problema dos motivos da ocupação. Sua elucidação permite verificar as "intenções coloniais", ou $s \in j a$, apurar o que se pretendeu fazer na Ilha da Madeira. Os documentos pontifícios ainda, ao reconhecer a posse e o exclusivo da Ilha, apresentam o fato como se fôsse um episódio de cruzada, de alargamento da cristandade. Os documentos das chancelarias têm um sentido de emprêsa política de apossamento de território. Mas, documentos há que nos dão a nítida impressão de organização de emprêsa econômico-política: os contratos, as sesmarias.

$3 .^{\circ}$ - No processo de ocupação, a quem toca a posse da Iiha da Madeira? Esse domínio é partilhado por via de doações hierarquisadas - ocorrem doações. Quem faz as doações, a que título as faz e para quem?

$4 .^{\circ}$ - Nas doações, que é que se dôa? Há um processo de delegação de autoridade? Que poderes são alienados e quais os que são reservados? Concretamente: o rei é o senhor da Ilha que se incorpora à Corôa. Êle a dôa a D. Henrique. Que é doado? O govêrmo. O govêrno integral? Que poderes o rei não delega? O Príncipe por sua vez dôa capitanias. Que significa isso? Dôa propriedade? Mas os capitães por sua vez doam também. A propriedade: quais os poderes do rei? Quais os do Príncipe? Quais os dos donatários? E os dos povoadores?

Desta análise, portanto, deve resultar a visão dos caracteres das instituições por via de comparação com o vigente em Portugal. São as instituições senhoriais do século XV que st: transplantam? São instituições novas que se experimentam com sentido de modernidade? Ou são instituições de transição, meio medievais, meio modernas - o velho com algo de novo? 
Estes problemas, de forma geral não têm sido abordados pcrque o estudo dos fatos da expansão, as precisões cronológicas indispensáveis têm absorvido os historiadores. As instituições coloniais e de colonização não têm sido objeto de indagações, em geral.

Assim os cronistas, como Zurara (1), Damião de Góis (2) ou João de Barros (3) falam numa descoberta acidental motivada por uma tormenta que teria levado os portuguêses a Pôrto Santo donde resolveram

"de ir ver se era terra hua grande sobra",

e aportaram em Machico. Outros falam num prévio conhecimento da Ilha cuja busca teria levado a Pôrto Santo. Tentam validar a "Lenda do Machim" numa de suas três variantes: a relação de Alcoforado, o Códice de Valentim Fernandes ou o Tratado dos Descobrimentos de Galvão.

Conforme Jordão de Freitas (4), em representações cartográficas da segunda metade do século XIV figuram as ilhas dc Arquipélago da Madeira, com nomes italianos, catalães ou espanhóis, conforme a nacionalidade do cartógrafo.

A data oscila entre 1418 e 1425 . Conforme Zurara (5) o escudeiro João Gonçalves e Tristão foram encaminhados

"em busca das terras da Guiné"

depois que o Infante fêz o descêrco de Ceuta (que, para Duarte Leite foi em 1419, e para Jordão de Freitas foi em 1418)

"e como Deus queria encaminhar tanto bem para êsse reino, e ainda para outras muitas partes, guiou-os assim que'com tempo contrário chegassem à ilha que agora se chama Pôrto Santo que é junto com a ilha da Madeira".

Conforme o testamento de Zarco, escrito na segunda metáde do século XV por Alcoforado, escudeiro do Infante, e que foi a escritura-mater para ọs trabalhos de Jerônimo Lei-

\footnotetext{
(1). - Gomes Eanes de Zurara, Crônica dos feitos da Guiné. Div. de Publ. e Bibl. Agência Geral das Colônias. Lisboa, 1949.

(2). - Damião de Góis, Crônica do Príncipe D. João. Imprensa da Universidade. Coimbra, 1905.

(3). - João de Barros, Décadas. Régia Oficina Tipográfica, Lisboa, 1777.

(4). - Jordão Apolinário de Freitas, Mađeira, Pôrto santo e Deserta. Ilhas que o Infante $D$. Henrique novamente achou e povoou. In Congresso do Mundo Português. Memórias e Comunicações apresentadas ao Congresso dos Descobrimentos e Colonização. 3.0 vol, III Congresso. 1a. secção: Descobrimentos Maritimos. Lisboa, 1940.
}

(5). - Op. cit., cap. LXXXIII. 
to (6), Gaspar Frutuoso (7), Manuel Tomaz (8), Francisco Manuel de Melo (9) e Antônio Cordeiro (10), os escudeiros partiram de Lisboa na entrada de junho à procura de Pôrto Santo, donde avistiaram alguma coisa que suspeitaram ser uma ilha. Saem a verificar e chegam à baía de Machico a 2 de julho, segunda-feira. Cronològicamente a primeira segunda-feira 2 de julho é do ano de 1425 .

Qual a entidade responsável pela descoberta? Para Frutuoso (11), o Infante, que

"desejando saber por experiência o que alcançara por arte, armou à sua custa certos navios e mandou com êles gente a descobrir aquela navegação e em diversas vêzes veio a ter notícias de gran parte daquela costa de terra firme e de algumas ilhas do Mar Atlântico... e então se descobriu a ilha da Madeira e a do Pôrto Santo e estas dos Açores".

Zurara (12) aponta a obra individual dos escudeiros João Gonçalves e Tristão Vaz para quem o Infante teria aparelhado uma barca. Na ilha de Pôrto Santo teriam encontrado condições favoráveis ao povoamento. Tornando, posteriormente, não conseguiram nela permanecer devido à grande quantidade de coelhos:

"deixaram aquela ilha e passaram à outra da Madeira, que será a quarenta léguas em cêrco e doze do Pôrto Santo e ali ficaram os dois João Gonçalves e Tristão". "Esta ilha acharam boa, especialmente de mui nobres águas corredias... e começaram ali de fazer suas sementeiras, mui grandes...".

Portanto, seria dos escudeiros a idéia da viagem e do povoamento.

"E tornando dali para o reino, falaram sôbre isso ao Infante, contando-lhe a bondade da terra, e o desêjo que

\footnotetext{
(6). - Descobrimento da Iha da Madeira.

(7). - Saudade da Terra, L II: "Sôbre a descoberta da Ilha da Madeira e adjacentes e vida e progênie de seus capitães". Ed. Damião Peres. Pôrto, 1926 .

(8). - Insulana.

(9). - Epanáforas de vária história portuguêsa, Epanáfora Amorosà Terceira: o descobrimento da Ilha da Madeira. Imprensa da Universidade, Coimbra, 1931.

(10). - História.

(11). - Op. cit.

(12), - Op. cit.
} 
tinham acêrca de sua povoação; de que ao Infante muito prouve, ordenando logo como pudessem haver as coisas que lhe cumpriam para se tornarem à dita ilha".

Segundo Godinho (13) deve-se rejeitar o pedido de autorização ao Infante, cuja atuação como príncipe autônomo não se enquadra nas concepções políticas da época. Nem nas concepções próprias de D. João, iniciador da expansão, e cioso de suas prerrogativas, para tornar pouco verossímil essa liberdade de iniciativa que se conferiu a D. Henrique. Possivelmente a Madeira seja o resultado da navegação para as $\mathrm{Ca}-$ nárias. Certamente, fruto do movimento expansional, iniciado pela Corôa. A Madeira é descoberta para o rei. A prova disso: a Carta Régia de 26 de setembro de 1433 que diz:

"as nossas ilhas da Madeira e do Pôrto Santo e da ilha Deserta que agora novamente o dito Infante per nossas autoridade pobora" (14). João I

O povoamento da Madeira se realizou em nome de $D$.

"e pedirão de novo autoridade minha para a poderem aproveitar"

diz ao falar do uso das terras uma Carta de Mercê inserta em Carta de Confirmação de 7 de maio de 1493 (15). E continua:

"pella quoal como Rey e senhor da dita ilha E todo o que nella ha, e de todo meu poder Regulado e absoluto lhes faso a dita Merçe para sempre como de cousa minha propria".

Estamos em pleno século XV, época de consolidação do poder real cuja concepção tinha implícita a idéia de patrimonialidade da terra em harmonia com as origens asturo-leonesas do reino português. Ao lado dêsse traço puramente medieval, encontramos, no mesmo documento, um caráter de modernidade na preocupação de legislar que o rei chama a si quando diz

(13). - Vitorino de Magalhães Godinho, Documentos sôbre a expansão portuguêsa. Vol. I. Editorial Gleba. Lisboa, 1943.

(14). - Grifos nossos.

(15). - In Descobrimentos portuguêses: documentos para a súa história. Publ. por J. M. da Silva Marques. Supl. ao vol. I. Instituto de Alta Cultura. Lisboa, 1944. 
"na dita ilha não usem nem pelo direito comum julguem nem sentenciem... e para isto faltar aqui alguma cláusula solene e essencial de direito ou de feito eu a supro e hei por suprida...".

$\mathrm{Na}$ Alta Idade Média o rei se preocupava apenas em fazer cumprir usos e foros: na Idade Moderna, o rei chama a si a tarefa de legislador. O fator transição é a nota dominante de tôda essa época henriquina. E' a côr esmaecida que torna pouco nítido o contôrno do quadrò institucional do XV século. E' a razão da persistência do medieval nas instituições da época dos descobrimentos, seculares que são as mudanças da hístória estrutural. Ao contrário das oscilações rápidas da história événementielle ou dos movimentos milenares do tempo geográfico.

O segundo ponto abrange o problema geral do Ultramar, a partir de 1415 . E se coloca em têrmos de cruzada ou expansão. A chegada à Madeira foi resultado do cruzadismo contra o infiel incentivado pelas Bulas que concediam privilégios espirituais além de legitimarem as terras arrancadas aos infiéis? Na Sane charissimus Martinho V em 4 de abril de 1418 (16) diz

"que todos os lugares que nesta expedição foram tomados aos bárbaros sejam acrescentados ao senhorio de D. João I, Rei de Portugal e seus sucessores...".

Eugênio IV na Preclaris tue devotionis em 25 de maio de 1437 (17) dirige-se a D. Duarte

"recomendando-lhe muito aquêle seu pio propósito, lhe concede por autoridade apostólica que êle e as pessoas a quem êle encarregar dessa missão possa exercer o comércio de quaisquer mercadorias, objetos e vitualhas com todos os sarracenos e infiéis..." e "...que não obstem a esta concessão quaisquer proibições, constituições, ordenações apostólicas...".

Nicolau V em 18 de junho de 1452 na Divino Amore (18) $\mathrm{d} \in \mathrm{u}$ a Afonso $\mathrm{V}$ províncias, ilhas, portos, mares por êle conquistados e proibiu o tráfico e comércio

"sem especial licença do mesmo rei D. Afonso de seus sucessores ou do Infante",

(16). - J. M. da Silva Marques, op. cit., vol. I. Lisboa, 1944.

(17). - Ibidem.

(18). - Tbidem. 
ameaçando de excomunhão pessoas, cidades, vilas e aldeias que não cumprirem suas determinações. Se aceitamos o critério de cruzada, a Madeira teve tratamento institucional medieval. Mas se pensarmos nas solicitações sócio-econômicas da época, vemos que a idéia da Madeira ter resultado da expansão marítima para o sul, está mais conforme à busca do equilíbrio financeiro em que se empenhava a Corôa desde D. Diniz. A expansão responde a uma convergência das necessidades de dilatação de território da nobreza senhorial e militar, com a da conquista de mercados pela burguesia mercantil que se instalura ao lado da realeza desde 1383. Não nos esqueçamos que Ceuta abrira aos portuguêses o Mediterrâneo comercial de Veneza, Gênova e Aragão. Descoberta a Madeira, estende-se a ela o regime senhorial remanescente no Portugal da época, por fälta de uma fórmula nova para uma situação nova. O princípio jurídico fundamental da Idade Média Peninsular deslocou-se para a terra ultramarina: à Corôa pertencia a Ilha como pertenceriam depois quaisquer terras, descobertas ou conquistadas, independentemente de sua natureza ou localização.

Como senhoreava a Corôa suas terras? O regime senhorial, fruto da situação ímpar da Reconquista, traduzia-se em doações reais. Doações feitas a uma Ordem Militar, a um grão-príncipe, a um conquistador ou descobridor. A primeira doação de que sé tem notícia na Madeira (inserta em carta de confirmação de 7 de maio de 1493) (19) parece tê-la distribuído

"aos novos povoadores da Ilha da Madeira que por meu mandado João Gonçalves Zarco foi distribuir que as terras the sejam sòmente dadas forras sem pensão alguma àquêles de maior qualidade e a outros que posansas tiverem para as aproveitarem, e aos de menor que vivam de seu trabalho...". Mais adiante diz que "as terras serão repartidas pelos capitães e as aproveitarão em dez anos...".

Julga-se que a doação é de 1426 . Do sistema não teria surtido o resultado esperado, ou a Corôa não se interessava em dispender reais de seu deficitário orçamento num lugar que ainda não lhe dava lucros, o certo é que a 25 de setembro de 1433

"Dom Duarte... querendo fazer graça e mercê ao Infante Don Henrique meu irmão, temos por bem e damos

(19). - Carta de Mercê inserta em Carta de Confirmação de 7 de maio de 1493. Publ. por Silva Marques, op. cit. 
lhe que tenha e haja de nós em todos os dias de sua vida as nossas ilhas a saber da Madeira...". "... assim como a nós de direito havemos e devemos haver..." (20).

O Rei dá as suas ilhas. A terra é propriedade coletiva vinculada ao Rei, único dono do solo. Se alguém a possui é por ter sido agraciado com sua concessão. Não reconhece qualquer direito a D. Henrique como promotor do descobrimento ou do povoamento. Segue a linha tradicional. O Rei dôa, porque tem o patrimônio da terra. Patrimonialidade territorial que associada ao patrimônio da autoridade, advém da Reconquista hispânica .

\begin{abstract}
"Originàriamente o reino pertencia ao monarca, em consonância com a acepção da realeza nos estados neogóticos, nos quais a concepção patrimonial do poder se desenvolveu, permitindo ao rei alienar livremente a jurisdição e outros atribuitos dêle como coisa sua, respeitada a integridade da soberania",
\end{abstract}

diz Oliveira França (21). Encontramos doações de terras, coutos e honras desde os primeiros tempos da monarquia portuguêsa. Assim o Conde D. Henrique dôa a Sueiro Mendes em 1097 coutos, atributos e regalias fiscais

(Concedimus... tibi... cunctas hereditates et homines... simul omne vestigale nostrum, tributumque et fiscalia regalitas... et in esto que tibi damus et in illo alio, que tu ibi habes ponimus tibi Cautum et facimus comissorium ut nullus homo per vim intus ingrediatur ad malefaciendum... nec pro peniore, nec pro Karacteribus, sed liberum, et ob solutum illum damus, etc.) (22).

Assim Sancho I em 1207 dando a Quinta de Vila Mãe

"com as calonas e todos nossos direitos" "et cunctus successoribus jure hereditario in perpetuum" (23).

Assim o foral de D. Afonso I à Vila de Moz em $1162 \mathrm{em}$ que se priva de tôda calona e da intervenção de seu meirinho:

\footnotetext{
(2C). - Chanc. de D. Duarte, liv. 1. ${ }^{\circ}$, fls. 18, cit. por V. Magalhães Godinho, op. cit.

(21). - o poder real em Portugal e as origens do absolutismo. Publicação da Faculdade de Filosofia, Ciências e Letras da Universidade de São Paulo. São Paulo, 1946.

(22). - Antônio Caetano do Amaral, Memória $V$ sôbre legislação e costumes de Portugal. Livraria da Cívilizaçãão Editóra. Pôrto, 1945.

(23). - Ibidem.
} 


\section{"et nullo preito, nec nulla calupmnia, nec intreb ibi nec meo Merino nisi Judice de vostro Concilio" (24).}

Êste sistema, que caracteriza os séculos médios, começa a " sofrer restrições no fim da Baixa Idade Média, restrições proporcionalmente diretas ao fortalecimento do poder real. Então, aparecem as inquirições e as correições. A doação da Madeira, Pôrto Santo e Deserta é a primeira de uma série que daria ao Infante

"O senhorio ultramarino com feições colonizadoras e mercantilistas, transição da estrutura social agricola, militarista e senhorial para o sistema de pigmentações burguesa e nítidas características comerciais",

segundo Manuel Nunes Dias afirma em seu trabalho sôbre o capitalismo monárquico português (25).

Diz a Carta Régia:

"que tenha e haja de nós em todos os dias de sua vida" (26) :

a terra lhe é dada como préstamo em usufruto vitalício.

"Com todos os direitos e rendas delas, com sua jurisdição civel e crime, salvo em setença de morte ou talhamento de membros mandamos que a alçada fique a nós; venha à casa do cível em Lisboa; outrossim lhe damos poder que êle possa mandar fazer nas ditas ilhas todos os proveitos e benfeitorias"... (27).

Ao Infante é concedido o uso da propriedade, isto é, o direito de trabalhar na terra e colhêr seus frutos, não o domínio dela. A doação do senhorio, isto é, o conjunto de faculdades que tinha o nobre a quem se havia concedido terras, dissociava a autoridade, que só parcialmente era delegada. A cessão régia conserva o jus eminens. Mantém-se a inalienabilidade da soberania, a incomunicabilidade dos bens da Corôa, haurida da legislação gótica. O rei mantém a suprema jurisdição. Ora, as funções judiciárias eram as destacadas tarefas dos reis. Segundo Oliveira França (28),

(24). - Ibidem.

(25). - Manuel Nunes Dias, o capitalismo monárquico português, 1415-1549. Subsídios para o estudo das origens do capitalismo moderno. Tese de doutoramento apresentada à Faculdade de Filosofia, Ciencias e Letras da Universidade de São Paulo. São Paulo, 1954.

(26). - Chac. de D. Duarte, liv. 1.0, fls. 18, cit. por V. M. Godinho, op. cit.

(27). - Tbidem.

(28). - Op. cit. 
"Justiça era o imperativo moral que obrigava o reinante como delegado de Deus. A idéia da justiça como dever ético e da injustiça como pecado, infundia na consciência dos reis cristãos, a imprescindibilidade de sua observância, pois que punha em jôgo sua própria salvaçấo eterna, e naquele tempo o temor da cólera divina era freio também para os governantes".

Com a reserva da justiça de que o rei era depositário pela vontade de Deus, concluimos não ter havido alienação da soberania. Dela, a justiça era um dos atributos essenciais. Os outros: defesa e fazenda (29). O mesmo documento régio concedia a D. Henrique o direito de

"aforar as ditas terras... sem prejuízo da forma do foro por nós dado às ditas ilhas em parte nem em todo nerm analheamento do dito foro" bem como "quitar parte ou todo o dito foro aos que vierem às ditas ilhas morar em sua vida do dito Infante...".

Se o Infante podia distribuir terras a quaisquer pessoas para sua exploração, o direito real era mantido pela pensão anteriormente estipulada. O soberano não abdica do seu patrimônio fiscal. Mas concede isenção dêsse seu direito pelo tempo de duração das mercês que está outorgando. Essas isenções, intrínsecas aos préstamos, eram a causa do desiquilíbrio do eráric real. Estão sendo repetidas, na cessão senhorial da Madeira, em plena época de orientação comercial monárquica, que era nitidamente burguesa.

"...com tanto que depois da morte do dito Infante êles paguem o dito foro..." "...se o dito Infante quitar o dito foro em sua vida a algum ou a algumas pessoas dos que forem às ditas terras... com tanto que quando a pessoa morrer seus herdeiros paguem logo o dito foro...".

Isto reforça o caráter de temporalidade da doação. E mostra o poder do Rei sôbre a Ilha. E lhe garante o direito sôbre os foros.

"E reservamos para nós que o dito Infante não possa mandar fazer em elas moeda, mas praz-nos que a nossa corra em elas...".

(29). - Conforme as Ordenações, em seu Título 26, Livro II, eram direitos reais: 1) criar cargos de milf́cia e justiça; 2) cunhar e bater moeda; 3) propriedade das coisas de uso comum. Direitos reais nas concessóes: encargos aos vassalos de serviço pessoal e serviço da fazenda e prestaçōes reais. 
O bater moeda era um dos direitos imprescritíveis da realeza (30). Compreende-se fàcilmente a reserva. Como se compreende que a Madeira e, de resto, todo o Ultramar, tomem a fcrma de um senhorio. A Corôa alienou parcela de sua autoridade, mas conservou os atributos da soberania: a suprema jurisdição, a prerrogativa de cunhar moedas, o direito. sôbre os foros. A Carta de 1433 é a cristalização das concepções régias medievais de D. Duarte. Doação confirmada pela Regência em 1 de junho de 1439 e por Afonso $V$ em 11 de março de 1449 . $\mathrm{Na}$ mesma data, 26 de setembro de 1433, o rei dôa o espiritual das ilhas da Madeira, Pôrto Santo e Deserta à Ordem de Cristo

"por o Infante D. Henrique meu irmão e regedor e governador da dita ordem que nô-lo requer..." (31). "...reservando que fique para nós e para a Corôa de nossos reinos o foro e o dízimo de todo pescado que se nas ditas ilhas matar".

A Ordem de Cristo, motor econômico da iniciativa ultramarina, precisa ser indenizada, mas a soberania real precisa ser reafirmada. Pede o outorgamento e a confirmação do Papa para a doação: isto é, seu reconhecimento à posse. D. Henrique é ainda detentor único da fabricação e comércio do sabão na Madeira. Monopólio que, como a posse da Ilha, estava limitado ao tempo de sua vida. Mas, que êle quis transformar em bens de juro e herdade quando, em 1436, faz seu primeiro testiamento e pede a confirmação de $\mathrm{D}$. Duarte da legação a seu filho adotivo, o Infante D. Fernando, das

"terras que tenho da Corôa do reino, assim como se fôsse meu filho lídimo próprio".

A confirmação de D. Duarte

"como se por direito melhor pode e deve fazer",

diz respeito às terras e aos bens vitalícios, uma vez que os de juro e herdade passariam automàticamente a $\mathrm{D}$. Fernando, como o diz o Pe. Dias Diniz em seus Estudos Henriquinos (32).

$\mathrm{Na}$ doação da Madeira fala o rei:

"outrossim lhe damos poder... de dar em perpétuo ou a tempo ou aforar tôdas as ditas terras a quem aprouver...",

(30). "- Henrique da Gama Barros, História da Administração Pública em Portugal nos séculos XII a XV. Ed. Livraria Sá Costa. Lisboa, 1945.

(31). - Livro das Escrituras da Ordem de Cristo do Dr. Pedralvas. In Alguns Documentos do Arquivo da Tôrre do Tombo, publ. por J. M. da Silva Marques. Lisboa, 1944.

(32). - Publ. Comemorativas ao Centenário do Infante D. Henrique. Lisboa, 1960. 
colocando o Príncipe como mediador entre a Corôa e os descobridores. Outro processo conforme aos esquemas medievais. D. Henrique, detentor do domínio da Madeira, delega êsse domínio a Gonçalves Zarco, Tristão Vaz Teixeira e Bartolomeu Perestrelo, com a confirmação de $\mathrm{D}$. Afonso $\mathrm{V}$ para a doação do Infante. A Carta de doação das capitanias, passada pelo $\mathrm{Na}$ vegador, confirmou oficialmente poderes que Zarco e Vaz exerciam, de acôrdo com instrução prèviamente recebidas.

A Carta de Doação de 8 de maio de 1440 cedia a Tristão Vaz a capitania de Machico, de juro e herdade

"morrendo êle a mim praz que seu filho primeiro ou segundo se tal fôr tenha êste encargo... e assim de descendente em descendente por linha direta".

Ao capitão era cedido:

1.0) - o dominio: "que êle a mantenha por mim...".

$2 .^{\circ}$ - a jurisdição: "... em esta sobredita terra a jurisdição por mim e em meu nome do civel e crime...". "...ressalvando a morte e talhamento de membro...". Portanto, mantida a justiça régia.

“...a mim praz que os mandados e correição sejam ai compridos...". Portanto, preservados os direitos do Infante, de correição. Que por sua vez não the pertenciam, mas ao rei. A correição era incomunicável. As leis não podiam concedê-la aos vassalos nem êstes usá-las sob pena de perda do préstamo. E' Caetano do Amaral (33) quem cita o rei D. Fernando: " $E$ ' porque a correição é sôbre a jurisdição como coisa, que esguarda o maior e mais alto senhorio, a que todos são sujeitos, assim é apresa, e ajuntada ao Principado, e poderio do Rei, que por nenhuma guisa não a pode de si quitar...".

3. o) - o monopólio dos moinhos de pão: “...e outrossim me praz que o dito Tristão haja para si todos os moinhos que houverem na parte desta ilha...". "...que ninguém não faça aí moinhos senão êle ou quem êle aprouver...".

4. $\left.{ }^{\circ}\right)$ - o monopólio dos fornos de pão: "que todos os fornos de pão em que houver pois sejam seus", atenuando: "...e porém não embargue quem quiser fornalha para seu pão que a faça e não para outro nenhum...".

5.0) - o décimo das rendas da Ilha devidas ao Infante: "que tudo o qué eu houver de renda da dita parte da ilha, que êle haja de dez um".

(3s). - Op. cit. 
6.0) - a prioridade da venda de sal: "...que tendo êle sal para vender o não possa vender outrém...". "...e quando não o tiver que vendam os das ilhas a sua vontade até que êle o tenha...".

O sal foi um dos mais antigos e apreciados monopólios fiscais da Corôa. Os monopólios dos senhores têm suas raízes no aparecimento do regime senhorial. Essses monopólios eram cedidos como mercês.

7.0) — o direito de doação de terras: “...que êle possa dar por suas cartas a terra desta parte forra pelo foral da ilha a quem lhe aprouver com tal condição que aquêle a quem der a dita terra a aproveite até cinco anos...". Mas faz restrições: “...e isso não embargue a mim que se houver terra por aproveitar que não seja doada, que eu a possa dar a quem por minha mercê fôr...".

Concessões do mesmo gênero são feitas em 1 de novembro -je 1446 a Perestrelo com a capitania de Pôrto Santo e a 1 de novembro de 1450 a Zarco, com a de Funchal. D. Henrique não ł⿳亠丷. aos capitães a soberania da terra, porque não podia dar o que não tinha. Os donatários gozam de privilégios reais, de värte do exercício do poder público sem que o Infante abdique to senhorio ou que o Rei renuncie à suprema jurisdição. Os poderes dos donatários foram sendo cassados nos anos que $s \in$ seguiram, como reflexo das tendências centralizadoras cadia rez mais fortes da Corôa. $\mathrm{Na}$ época de seu aparecimento, o sistema de donatárias constituiu fecunda adaptação das doações tos bens da Corôa. Idêntico sistema foi usado nos Açores e demais ilhas Attânticas por não ter sido possível a exploração co. mercial imediata ao descobrimento. A autoridade real garantia as mercês dadas aos

moradores e novos povoadores da dita ilha em ra. sav ae a irem povoar e deixarem suas terras e pattrias... *

$\mathbb{E}^{\prime \prime}$ ainda Jerônimo Dias Leite quem diz (34):

"El Rei Don Afonso, quinto do nome, deu a essa Vila do Funchal muitos e bons forais e liberdades...". E "Ca. pitão Zargo a quem El-Rei fêz mercê da capitania da jurisdição do Funchal de juro e herdade para êle e seus sucessores"... ..."Dizem que deu a Capitania de Pôrto santo a um Bartolomeu Perestrelo a petição do Infante עon Henrique de cuja casa era fidalgo" (35).

(34). - Op. cit.

(35). - Ibidem. 
Diz ainda Dias Leite:

\author{
"Tinha el-rei e o. Infante avisos cada mês da fertili- \\ dade e frescura da Ilha" (36).
}

Firmada a permanência das duas jurisdições.

D. Henrique, por carta régia de 1 de junho de 1419 recebe a isenção das dízimas de portagens no comércio da Madeira com - Reino. Isenção que procura fomentar o comércio. Sem esquecer a influência política da Casa Senhorial do Infante, tão importante na época de transição para a Regência. A 22 de outubro de 1433 recebe a cessão do monopólio do tráfico para o sul do Bojador, com isenção do quinto e dízima:

"ninguém não passe além do cabo de Bojador sem seu mandado e licença e os que passarem nos praz que percam tudo o que de lá trouxerem".

Estranha concessão. Espécie de prêmio que não se enquadra com a política da burguesia urbana praticada pelo Regente. Talvez episódio da luta político-social do século $\mathrm{XV}$, que se justifica pela ausência de capitais da Corôa e pela riqueza da Ordem de Cristo.

$\mathrm{Da}$ leitura dos documentos relativos à Madeira fica-nos a idéia de que na Ilha foi aplicado o regime senhorial. A Madeira foi um senhorio como tantos outros existentes em Portugal nos séculos médios, por falta de uma fórmula nova para uma situação nova.

Com a morte do Infante a Madeira reverteu à Corôa? D. Afonso $\mathrm{V}$ parece ter forçado o Infante a torná-lo seu herdeiro. E' o que nos mostra seu segundo testamento feito a 28 de outubro de 1460:

"peço a el-rei meu senhor por mercê que êle queira ser meu testamenteiro, porque seu é todo o de que eu faço êste testamento..." (37).

Recomenda ao rei a doação de qualquer outro bem ao infánte D. Fernando

"e do que êle mais do que ficar de mim quiser dar lho terei em mercê reservando Lagos e a ilha da Madeira... que the prouve de querer que ficassem para a sua Corôa e de seus sucessores...".

(36). - Ibidem.

(37). - Op. cit. 
O Infante perde a temporalidade da Madeira. O interêsse de Afonso $V$ na Madeira pode ser encarado como um traço de centralização? A explicação, segundo o pe. Dias Diniz (38) estaria na tensão das relações entre D. Fernando e Afonso V depois de 1451, ou mais provàvelmente no déficit da fazenda régia depois de 1460 . Seus fundos teriam sido consumidos no acalmar as desinteligências surgidas no reino depois de $D$. Duarte, nas campanhas marroquinas, em dotes, tenças, moradias e assentamentos vitalícios. Cremos não encontrar ainda traço de modernismo na política de Afonso $\mathrm{V}$ em relação à Itha, pois a 3 de dezembro de 1460 , concede-a

"considerando nós as muitas virtudes do Infante D. Fernando, meu muito prezado irmão, e nos singulares serviços que com muita lealdade nos sempre fêz e ao diante esperamos dêle receber; e de si esguardando ao grande amor e singular afeição que a êle temos e as razões que nos movem e o muito amor e lhe fazemos muitas mercês o acrescentarmos segundo requer a grandeza de seu estado e nos obriga a grande dívida que com êle temos, da nossa livre vontade, certa ciência, poder absoluto, sem nô-lo êle pedindo nem outrém por êle, temos por bem..." (39).

Essa doação e as outras que se seguiram que deram a D. Fernando os monopólios retidos por D. Henrique, suas terras, ilhas, etc. além de doações novas feitas ao filho adotivo do Infante serviram para aumentar sua riqueza, influência e supremacia. Quando pensamos nos benefícios que a centralização da Madeira poderia trazer ao rei. celeiro precioso que era para provimento dos barcos que iam para as costas da Africa, inferimos a fôrça política que D. Fernando devia representar. Ou o grau de apôio que devia ter na nobreza da época.

D. João II ao doar a Ilha a $\mathrm{D}$. Manuel diz que

"a Madeira no que pertencia a sua Corôa, êle Duque a teria em sua vida inteiramente mas que por seu falecimento, quando Deus ordenasse, era razão, que por ser coisa tamanha, se tornasse à Corôa e aos reis desta".

A centralização, aqui delineada se dá sob D. Manuel que a 18 de outubro de $1496 \mathrm{diz}$ em carta régia:

(38). - Op. cit.

(39). - Carta de doação feita por $D$. Afonso $V$ a seu irmão o Infante $D$. Fernando das Ilhas da Madeira, Pôrto Santo e Açores. Chanc. de D. Afonso V, 1, 1.0. Cf. Silva Marques, Documentos. 
"considerando nós a muita nobreza da nossa ilha da Madeira... como do muito proveito que dela vem a nossos reinos... que nunca em nenhum tempo daqui em diante deve ser dada a pessoa alguma mas sempre ser nossa... e assim mandamos e encomendamos a todos os nossos sucessores dêstes reinos que depois de nós vierem sob pena de nossa bênção que à dita nossa ilha da Madeira que nunca a tirem de si nem a pessoa alguma nem a filho primogênito como dito é porque assim o sentimos...".

E' ainda com D. Manuel que, reduzidos os poderes dos donatários, são êles finalmente subordinados ao rei, perdend.) suas atribuiçc̃es militares e judiciais.

\section{III. - Linhas de pesquisa.}

Resta-nos uma palavra sôbre a inexistência de obras de história institucional, exceção feita à História da Administração Pública em Portugal de Gama Barros, e à História das Instituliçũes em Portugal de Fortunato de Almeida, e dos recentes Estudos Henriquinos do Pe. Dias Diniz. Os elementos para uma história institucional da época dos descobrimentos só podem ser encontrados dispersos na abundante bibliografia existente sôbre os fatos da expansão. nados:

$\mathrm{E}$ ainda sugerir uns possíveis ramos de pesquisa, origi-

$1 .^{\circ}$ - Da necessidade de ligar o medieval à época dos describrimentos, isto é, o problema da persistência das instituições;

$20^{\circ}$ - Da necessidade de estudar a organização da colonização, isto é, o problema das estruturas;

$3,^{\circ}$ - Da necessidade de estudar as ideologias, isto é, o problema das idéias cambiantes que inspiram a colonização;

$4 .^{\circ}$ - Da necessidade do reexame dos documentos oficiais sôbre a colonização e de depoimentos contemporâneos;

$5 .^{\circ}-$ Da necessidade de monografias em profundidade para conhecimento das áreas e épocas sucessivas de institucionalização da colonização (fenômeno moderno) para a compreensão da seqüência das experiências. Um exemplo disso temos nas Ilhas e Capitanias no Brasil.

SôNIA APARECIDA SIOUTIRA

Professôra de História Ibérica da Faculdade de Filosofia, Ciências e Letras de Taubaté.

Revista de História n. 48. 